OPEN ACCESS

Citation: Ernst S. (2021) Anti-discrimination and diversity at school. Findings from the evaluation of an organizational implementation process, in "Cambio. Rivista sulle trasformazioni sociali», Vol. 11, n. 21: 91-102. doi: 10.36253/ cambio-11574

Copyright: (c) 2021 Ernst S. This is an open access, peer-reviewed article published by Firenze University Press (http://www.fupress.com/cambio) and distributed under the terms of the Creative Commons Attribution License, which permits unrestricted use, distribution, and reproduction in any medium, provided the original author and source are credited.

Data Availability Statement: All relevant data are within the paper and its Supporting Information files.

Competing Interests: The Author(s) declare(s) no conflict of interest.
Eliasian Themes

\section{Anti-discrimination and diversity at school. Findings from the evaluation of an organizational implementation process}

\author{
Stefanie ERnst \\ Westfälische Wilhelms-Universität Münster \\ stefanie.ernst@uni-muenster.de
}

\begin{abstract}
Current diversity and anti-discrimination policies are the result of intended and non-intended long-term social movements and changes. This implicates informalisation processes as well as formalisation processes of organizations, in which sexism, racism, homophobia etc. are blamed and fought. In this context, the presented EU-Project SPRYNG consists of several data about the cognitive structure as well as the awareness of discrimination in order to support organizational diversity learning. Based on The Established and Outsiders and the process-theoretical debate on diminishing power differences, informality and equality, the paper presents a snapshot of discrimination in educational organizations (schools) and society. The data (survey and expert interviews) give insights into the perception of discrimination. As part of organizational change processes, these collected data supported the discussion about "sensitive and good school culture". The paper reports about the results, pitfalls and theoretical implications of anti-discrimination politics in the area of education as part of organizational integration politics.
\end{abstract}

Keywords: organizational change, anti-discrimination, process theory, informalisation, school culture.

\section{INTRODUCTION}

Since the social tensions that broke out in the 1970s, long-term social mobility processes have been triggered that have not only left behind an increased sensitivity to inequality and internalized norms of justice. Rather, social inequalities are renegotiated under the label of diversity on the one hand and discrimination on the other and systematically dealt with institutionally. Organizations are therefore faced with specific requirements not only to design this diversity-sensitive change in a constructive manner, but also to use specific control elements. The extent to which hierarchical organizations that permanently reproduce inequality are able to balance 
both expectations of equality and singularity is an empirical-theoretical question. In particular, the norm notions provide protection from discrimination and the promotion of diversity with the General Equal Treatment Act (AGG 2020). In addition, the European Charter of Diversity offers a binding legal framework for operational practice. In the special case of educational organizations as institutions, this is much more difficult, because discrimination-critical approaches find acceptance with a delay. However, even 14 years after the introduction of the AGG, there is still a high need for research and further training (Gomolla 2019; Foitzik, Hezel 2019).

School, as a special organization, has its own logic that is shaped by "local idiosyncrasies" (Gomolla 2019:121) and actor constellations. For change processes, not only "extensive legitimizing, financial, time and technical resources" are required. Rather, they are also contradictory, "laborious and often conflictual” (Gomolla 2019:121). If, therefore, discrimination is required as a central requirement for action in all school work areas, in which routines have to be shaken from time to time (te Poel 2018), the question must be asked what this means for the concrete organizational practice of school. Against this background, the presented European evaluation project SPRYNG ${ }^{1}$ both reflects on the process-structure of a discrimination-sensitive school development and examines the extent to which school culture can mediate school development processes and conflict regulation. The offered organizational sociological view of school power networks and discrimination processes not only illuminates the skill levels of educational learning cultures, but also unintended consequences of organizational development. In the course of the project, balances of tension became visible, which indicate a close connection between the general school climate and well-being. Identifying school as a figuration with its specific norms, rules and social tensions in this context helps to understand the span of formalisation and informalisation in relation to serve social needs: feelings of belonging and exclusion, superiority, inferiority and discrimination. It is therefore important to recognize the blind game of dominant social trends and counter-trends, changing power balances and functional equivalents (Elias 2008; Ernst 2010: 77). Social change is not exactly planned by individuals, but shows a recognisable pattern. Although it can be best understood best retrospectively, in the following analysis I try to reflect medium-term social changes that took place since Equality politics have been introduced in Western societies since the 1980ies as part of functional democratisation and informalisation processes. Furthermore, choosing the perspective of interdependencies, one can reconstruct the socio- and psychogenetic dimensions of gender and diversity from a higher level (Ernst 2013).

Applied to our project, especially sexual orientation, gender and social origin are present in the consciousness of the analyzed groups. Participant-oriented processes that rely on synergy effects between school quality and school culture, however, sometimes encounter institutional barriers that refer to the hierarchical process structure of the school system. In order to design a diversity-sensitive approach for school development, the anti-discrimination strategy is described below. After the project design has been carried out, the imparting of reflexive discrimination knowledge is presented using exemplary results. It becomes clear that the discussion and administration of discrimination in schools is not only "potentially filled with uncertainty and taboos" (Gomolla 2019:119). Creating a reflexive awareness of discrimination is subject to a reification of difference at the moment it is addressed. This double bind also takes place in a work-intensive field that is under permanent social observation.

\section{THEORETICAL APPROACH}

A famous quotation by Elias and Scotson describes best the environment and double binds of nowadays organizations which are embedded in a "complex polyphony of the movement of rising and declining groups over time" (Elias/Scotson 2008: 20). During these, one may say, 'civilisation offensive' outsider groups successfully entered positions "previously denied them" (ibid.). The focus of our project therefore laid on these long-term processes that

\footnotetext{
${ }^{1}$ I would like to thank Dr. Filippo Buccarelli, University of Florence, for the transnational project management, the comparative data analysis and the successful cooperation. All quotations from German sources have been translated by the author.
} 
are "still largely concealed from view" (ibid). Knowing that a long-term analysis of the spurts of informalisation and formalisation can't be demonstrated in this paper, only a snapshot of contemporary social conflicts can be delivered. Instead, the emotional debates on discrimination, sexisms, racisms etc. will be reported from the perspective of witnesses, experts and victims of discrimination. Underprivileged groups are dependent on formalisation processes in law (EU-Charta Diversity, Anti-Discrimination Law) as well as on informalisation processes like empowerment networks to gain more rights, democratic participation, equality and acceptance. A symptomatic insecurity and dynamic of human relationships in this context go hand in hand with growing individualisation processes of previously less powerful groups. The span of power balance between the sexes or between hetero-, bi-, trans- and homosexuals is constantly being negotiated, because power relationships fluctuate:

"In so far as we are more dependent on others than they are on us, more directed by others than they are by us, they have power over us, whether we have become dependent on them by their use of naked force or by our need to be loved, money, healing, status, a career, or simply for excitement" (Elias 1978: 93).

Organizations are thus primarily seen here as figurations with a view to their specific socio- and psychogenetic interrelationships, which are constantly changing and show shifts in power that can be described as dynamic balances of tension (Ernst 2010; Becke, Ernst 2019). For example, for decades, the struggle for equality understandable as an informality-formality span (Wouters 2014) is presented, in which institutional personnel policy organizational practices already embody egalitarian figuration ideals on the one hand. On the other, an astonishing perseverance against the legitimate participation of qualified women or migrants predominates, producing peculiar socio-dynamics. Who, really wonders that this hidden span massively became obvious for example in the battle surrounding “\#MeToo" or "Black Lives Matter". Despite all formal equal rights this disputes very openly indicate hidden patterns of informal and often institutional discrimination practices interwoven with "inherent feelings of superiority and inferiority" (Wouters 2014) and concealed from view. Informal conflicts, which were previously taboo, are negotiated in sometimes lengthy processes and gradually formalised. In this context, especially Wouters asks whether we can find a decrease of civilized and democratic standards. Basic to process theory is the relation between external and self-constraints ${ }^{2}$ also focusing the dynamic emotional balance of social groups, i.e. men and women in different arenas such as business or private life (Ernst 2003b; Wouters 2014). In my perspective this lack of democracy becomes clear especially by analysing 1960 s sexual revolution which was ambivalent until today because it implied relatively more advantages for heterosexual men then for women.

This briefly described figurational environment was the context of our EU project SRYNG with its focus on the "Spreading Young Generation" fighting discrimination. Based on the concepts of gendered and stratified organizations, additionally, the structural interweaving of diverse inequalities (Ernst 2013, Supik 2017) can be prepared for the implementation of reflective, discrimination-critical work (Mecheril, Tißberger 2013). Whilst process theory shows the socio-dynamics of stigmatization with the already widely used model of Established-Outsider Figuration (Elias, Scotson 2008; Ernst 2010), the othering approach allows to integrate the 'critical race theory' and ongoing construction processes. At the same time, the structure of socio-dynamic stigmatization typical for power dynamics between unequal groups persists. Hereby, stereotypical differences can be renewed as well as broken through at the moment they are discussed. Here, different forms of knowledge (implicit, explicit, semantic or empirical knowledge; Böhle 2019) that are relevant for the conceptualization of discrimination knowledge are also enacted. The process of imparting knowledge about discrimination and diversity and exploring the formal conditions for discrimination-sensitive work was shaped in the project presented by official path developments. The intensification of work that was initially always associated with social innovations threatened to develop into a permanent state.

\footnotetext{
${ }^{2}$ Different levels of social control describe the civilisation process in this context: control over oneself, over others and over nature, the mutual reduction of social contrasts while increasing diversity (Wouters 2014).
} 


\section{Anti-discrimination and Diversity as challenge for schools}

Compared to the change from collective concepts of equality and justice to equal opportunities, newer, individualizing concepts separate equality, difference and justice (Ernst 2013). Diversity, in this context, has advanced to become common terms; this is the attempt to experience equal opportunities at school. The diversity debate alternates between inclusion, integration and diversity, or fairness of performance and fairness in individual cases. The politics of diversity deriving from these semantics range from a close understanding of inclusion and acculturation through an utilitarian understanding to the defensive negation of difference (Ernst 2013). In school, knowledge of policy administration can only be translated into recommendations for action (Foitzik, Hezel 2019). The dynamics of these long-term "complex polyphony of the movement of rising and declining groups" (Elias, Scotson 2008: 20) have promoted anti-discrimination policies. This caused established groups to fear loss of privileges, while ascending outsiders were fighting for participation and recognition in educational advancement. However, counter-movements continue against social learning processes and transformations (El-Mafaalani 2018; Treibel 2017). Organizational change processes tie in with these societal process dynamics by working against stereotyping and internalized power asymmetries through diversity learning (Hauenschild et al. 2013; Ernst 2013). The ambitious goal of reaching non-discriminatory society often underestimates the specific dynamics of ongoing diversification. Because stereotypes express internalized power relationships it needs deep changes of behavior. Schools, as a special case of organization, operate against this background as an explicitly learning organization with few rights that can be standardized. From an organizational sociological point of view, the bureaucratic structure of schools serves the purpose of gaining rights to responsibility and administration (Drepper, Tacke 2012). Guidelines are mediators of school culture and development, and can tie in the European Charter of Diversity and directives of the General Equal Treatment Act (AGG) in Germany.

In this context, direct discrimination occurs when "one person (...) receives less favorable treatment than another person in a comparable situation” (AGG 2020, \$3). Indirect discrimination initially appears neutral and primarily means regulations, criteria or procedures that exclude a certain group of people, which is why one speaks of institutional discrimination. This can range from cultural stereotypes and "disparaging discussion of diverse languages in the classroom” (Foitzik et al. 2019: 209) to demotivate school career counselling, problematic learning materials, bullying and sexual harassment, for which hardly any complaint points exist. Therefore, the mere ascription of a characteristic is not sufficient to establish discrimination, because the effect on the discriminated person is decisive here. However, intersectional social research makes it clear that plural discrimination features can work at the same time and are all the more difficult to grasp (Supik 2017). From a social science perspective, discrimination focuses on the fact that 'being different' corresponds to unequal treatment, which is considered a legitimate distinction. It also includes that "economic, political and legal disadvantages are not seen as a problematic override of the principle of equality and equality of all individuals, but as an acceptable consequence of the difference in the respective group" (Hormel, Scherr 2016: 299 ff.).

Transferred to school quality, discrimination-sensitive school development can be understood as both educational and sociological organizational development and a school policy mandate. On the one hand, school is a bureaucratic organization that is characterized by multiple interaction processes. These take place with parents, students, teachers, school management, interest groups, the municipality and local businesses etc. From a professionsociological point of view, the unbounded and subjectivized teaching profession is thus practiced and assessed in a micro-diverse and insecure environment. Massive time pressure in the dense everyday school life, a continuous assessment system and documentation obligations accompanied by growing demands to encourage students individually and to treat them equally and fairly, make comprehensive quality development procedures difficult. School therefore pursues paradoxical organizational goals by combining an educational sociological selection and allocation function with the requirement and expectation of equal opportunities and equality (Drepper, Tacke 2012; Herzog 2011). Due to the discourse about governance and quality in recent decades, evaluation for schools has also been used as a question of external presentation and control of whether and how school learning and development goals are achieved (Ernst 2003a, Sowada, Peetz 2019; Foitzik et al. 2019: 200 f.). In this structure, which is based 
on homogeneity and heterogeneity at the same time, anti-discrimination measures or diversity learning are an additional challenge in that one has to switch from equal treatment to distinction without excluding. This pedagogical balancing act is by no means automatically given in teaching practice, because although discrimination is legally defined, "an appropriate pedagogical approach cannot be derived from the legal understanding of discrimination" (Foitzik, Hezel 2019: 13). School ultimately harbors special structural challenges "in the field of tension and in dealing with its state and professional framework", which teachers can also experience as "demands and limitations of professional possibilities" (Drepper, Tacke 2012: 231). An expanded understanding of diversity in this structure particularly requires a look at the socio-dynamics of social differences. School functions both as an educational authority and as a legal, administrative, organizational and training address as well as a "personality-shaping place in the individual résumé" (Drepper, Tacke 2012:232). As an institution, it is responsible for fulfilling the legal education and training mandate and is not a voluntary offer due to the compulsory education.

As a labor organization, the point of contact for the AGG, schools represent a specific figuration in which teachers are particularly in demand for their pedagogical skills. In the context of the EU Diversity Charter and the AGG, the federal school law in North- Rhine-Westphalia focuses on hazards at the workplace such as accident prevention (NRW School Law 2019: Section 59, Paragraph 8). Moreover, it is primarily aimed at schoolchildren when they are supposed to learn "to meet people of different origins without prejudice, to get to know and reflect on the values of different cultures and to stand up for peaceful and non-discriminatory coexistence" (NRW School Act 2019: §2). This means that young people can mostly be addressed indirectly via the school culture. Furthermore, the educational diversity debate, operates with the distinction between primary dimensions (age, gender, skin color, impairment, sexual orientation) and secondary dimensions (income, education, occupation, marital status) in order to mark processes of socialization and identity formation (Kaluza 2017). Contrary to the controversial setting of primary and secondary dimensions, the aspect of changeability stands out, which makes discrimination as a process workable. In this sense, using school heterogeneity constructively means seeing diversity and difference as enrichment instead of deficit, "focusing on oneself" and particularly reflecting on "differentiating decisions" (Kaluza 2017: 199 f.). Against this background, the project design initially relied on teachers to be sensitized by reflecting on their own discriminatory behavior and then passing on the discriminatory knowledge gained to students. The accompanying scientific research on discrimination is presented below.

\section{QUALIFICATION AND PROCESS EVALUATION}

Embedded in this briefly sketched debate (Hauenschild et al. 2013), the research design was complex: it included an 80-hour qualification of teachers with an accompanying survey of the population ${ }^{3}$, the pupils and experts from politics, administration and self-help-groups. In the first step schools with the primary target groups of young people and teachers were defined as the central field of interaction. To address pupils (between 12 and 19 years old) as a special group was important because:

\footnotetext{
"The status consciousness of children, (...) is, if anything, even stronger than that of adults. The assurance which a person gains as a child from the belief in the high status of his family often enough colours his self-assurance in later life even if his own status is less well assured or has become lower. In the same way the experience of a low status attributed to a child's family will leave its traces in his self-image and self-assurance in later life." (Elias, Scotson 2008 [1965], appendix: 175f.)
}

The qualification of the teachers was initially based on a two-day workshop per month in which knowledge of discrimination was imparted in individual modules (local needs, legal situation, prejudices and structures as well as measures). As a result, school information and communication campaigns, documentation and a Italian-German final conference were implemented. The project was rounded off with the creation of an instrument kit for schools

\footnotetext{
${ }^{3}$ All following evaluations are based on the internal evaluation data (Ernst et al. 2020). Quantitative questioning was predetermined by the EU questionnaire and was modified for our needs.
} 
and the evaluation of the courses. The teachers were provided with up-to-date regional survey data on the spread, perception and interpretation of discrimination as well as suggestions for school development in order to work with the young people to derive fields of action for policy on discrimination. A permanent peer-to-peer coaching between school conflict and anti-discrimination guides and teachers rounded off the project. Another criterion was whether an anti-discrimination measure can be implemented realistically and permanently in everyday school life.

\section{Perception and assessment of discrimination ${ }^{4}$ : comparison of the population and pupil survey}

In a representative random selection, 228 residents of the administrative district were questioned through telephone interviews, while 97 pupils of the four participating schools could be interviewed. First of all, selected data show that discrimination is recognized as a social fact. As expected, people observe, experience, perceive and interpret discrimination differently. Implicit discrimination knowledge can be seen insofar as up to $40 \%$ of the inhabitants observed cases of origin-related discrimination, followed by $29 \%$ religious and $22 \%$ gender-specific cases of discrimination. In comparison, students gave similarly high values for the origin factor at $43 \%$. Contrary, age and gender discrimination were perceived much less in this group than in the population survey. This could be a hint towards increased gender equality or a higher equality awareness in the (post-material) youth, proofed in several youth studies too (Calmbach et al. 2020). Both groups (63\% students and $57 \%$ of the population) report that they have experienced less or no discrimination what may be seen as an emancipation success. Concerning their expert knowledge, nonetheless, $20 \%$ of the inhabitants analyses the respective sexual orientation as a reason for persistent discrimination. But the impression of social equalization remains ambivalent: men and persons under the age of 30 were assessed as hardly discriminated against. Looking at formalized processes in law, institutional practices and measures the fight against discrimination in the population survey is valuated as sufficient and successful for age $(84 \%)$, followed by gender (83\%), disability (80\%), religion $(77 \%)$ and origin (76\%). On the one hand, gains in emancipation and gender equality measures were identified as an effective counter-reaction to social power inequalities. Here, planned and organized processes of formalisation favored underprivileged groups as part of a long-term social change. On the other hand, there was still a great need for action, because $66 \%$ of those surveyed were unfamiliar with the AGG. In addition, for $56 \%$ sexual orientation and gender identity remained important tasks, which for $90 \%$ of these respondents manifested themselves particularly in the segregated housing market. In contrast, $58 \%$ of the students considered measures against discrimination to be effective, but only $31 \%$ knew the AGG, which indicated a need for information. Depending on the personal experience of discrimination, the help and advice system was used differently. For a total of $42 \%$ of those surveyed, their personal network was initially important if one was discriminated against. Crosstab-analysis of the factor experienced discrimination and potential use of institutional contact points showed a relatively strong legal awareness: $28 \%$ of those who had experienced gender-related discrimination had already consulted a lawyer, while only $19 \%$ of all respondents would do so.

Furthermore, 37\% of gender-discriminated people are more likely to turn to the police. While lawyers and the police were only relatively trusted, the respondents found trade union (for 6\%) or organizational offers (for 12\%) hardly suitable in comparison. Another strong finding is that questioned who have already been discriminated against do not turn to a corresponding contact point: $80 \%$ because of gender, $84 \%$ because of handicaps, and $89 \%$ because of their origin (89\%). Only $11 \%$ of those sexually discriminated would turn to an internal complaint point at the workplace, while $89 \%$ refused. None of the people who have been discriminated against on the basis of their origin or gender identity would turn to an internal complaint point, while $14 \%$ of those discriminated against in terms of age would do so. Here, the lack of information about German and European policies and directives stresses the need for better institutional collaboration on the basis of survey data. Moreover, the plausible requirement to set up complaint or contact points seems worth considering in view of this low level of trust, especially if complaints are seen more as an organizational disruptive factor. However, according to Foitzik (2019: 116 ff.), more

${ }^{4}$ More detailed evaluation data (Ernst 2021). 
explicit regulations and complaint management structures as well as differentiated procedures and sanctions should provide relief. At the same time, the areas of tension hidden behind remain to be explored further. In contrast, the virtual space of the Internet is a comparatively stronger point of contact, favored by $27 \%$ of the respondents who were discriminated against on the basis of their gender. On the other hand, no one of those who have been discriminated against due to their origin or sexually would resort to advice on the Internet, which could reveal information on the more informal status of this category of inequality. One could also assume that after 30 years of active gender equality policy, gender is a socially and institutionally more recognized category of inequality than the comparatively younger identity category. The findings on origin, on the other hand, remain more ambivalent, since they point to a more well-known, but solidified inequality situation, which is likely to be shamefully concealed as a kind of an "unsolved"' inclusion problem. In comparison, $73 \%$ of students preferred confiding to friends and family in the event of discrimination, followed by $28 \%$ (trusted) teachers as contact persons. The police were an option for $18 \%$, followed by classmates (16\%), advisory services (7\%) and internet services (2\%).

\section{School-Development and Social Tensions}

In order to described a middle-term social development concerning equality and discrimination we asked our experts in how far social change had taken place in their view and how they judge these developments over the past 25 years. In comparison to the population and pupil survey, these data consist of experts ${ }^{5}$ worked in administration, politics and civil society organizations. They were asked how they rate the gender equality policy measures (i.e. AGG) and how they explain the phenomenon of discrimination. In relation to the various dimensions of discrimination, i.e. sexual orientation, migration and gender, a politicized understanding and expert knowledge can be identified on the one hand. Moreover, this could be interpreted as successful emancipation process with increased mutual identification between established and outsider groups. Furthermore, as part of undirected but nevertheless intended social change, the public pressure of social liberation movements has manifested in institutional practices to govern equality policies. The span of diagnoses, our experts offered, varied between a "gender equality policy hype" (AD_3: 13) to characterize the 1990ies up to its nowadays oversaturation on the one hand. On the other, as long-term effect, at least a climate for open discussions of sexual identities has developed. Despite these changes of discussion culture, the taboo subject of homosexuality is still overlooked at school, especially in the form of cyber bullying. One student who is engaged in a youth club argued, although since 2001 it has been "in the curriculum that the topic of sexual discrimination is to be treated equally, and has to be conveyed", actually nothing happens (JC_1: 47). He identifies one reason in "the so-called concerned parents who fear early sexualization of their children" (JC_1: 129) and thereby defend the heteronormative ideal of family.

Furthermore, the answers of our experts pointed to a wide range of symptoms associated with persistent discrimination reflecting the ambivalent forward and backward movements of equality between social groups. The complex and contradictory situation ranged from growing tolerance and subtle discrimination as well as overt violence against teachers and students (SP_1: 111-155).

Also, in relation to the gender dimension this ambivalence of moving forward and backward continues: opened access to education and labor market, increased equality and social recognition of women goes hand in hand with enduring (cruel) struggles: an expert from an emergency call states that despite progress in equality, there exist "reintensified myths and sexism; Victims of violence [again count again] as contributors" (BF_1: 81). Similar to this, a politician classified Germany as an open society and identified "wave movements" (PD_2: 185) of progress as well as setbacks of gender equality: in her view "defensive battles" and "breaking of taboos" happen again. (ibid.: 133).

These exemplar social diagnoses of our experts were presented to several actors in school, community and administration in a second step as the project included organizational learning goals. Contrary to the experts, the reactions of the schools to the diversity requirements were often ambivalent. These not only refers to known tensions

\footnotetext{
${ }^{5}$ The interviews were prepared with MAXQDA, anonymised with acronyms and bundled in a focused content analysis.
} 
and inscribed functional logic in action research settings. Especially when synergy effects are to be generated with the development of school quality and school culture ${ }^{6}$, the pitfalls of participant-oriented procedures in hierarchical organizations became obvious (Ernst 2010). In order to further identify organizational links for school anti-discrimination work and to develop indicators for 'good school culture', the statements of additional experts, especially from school psychological counseling centers on the 'school climate', are instructive. A grouping of teachers was identified in which, on the one hand, there are "teachers who look very closely, they explain things, they always talk about everything promptly, because it is embedded somewhere in the school culture" of diversity. On the other hand, "unfortunately there is a percentage of black sheep" and a "climate of looking away. Here, it is not good when we talk about bullying and discrimination" (SP_1: 72-74). Because organizational contexts create the basis for a discrimination-sensitive school culture and differ greatly, teachers have "of course a model effect" that must also "be addressed in teacher training" (SP_1: 72-74). Implementation difficulties would arise if innovative projects were mainly transferred to young teachers or new trainee teachers, whilst the entire staff continues to block innovations. In addition, a high work density is a problem that develops due to uncoordinated anti-discrimination measures in schools in addition to extensive school prevention work. In a heterogeneous school community, particular stamina and frustration tolerance are also indispensable in order not only to resolutely counter "rigid role models, sexism and racism" and cyber bullying.

This implementation in ongoing campaigns and projects, which many schools undertake not only in the school models, but also in campaign days and project weeks, supports the idea of taking up further innovative anti-discrimination projects. However, according to the counselor's assessment, the stress stemming from "exhaustion, illness, and uncertainty about >what can I do now?" (SP_1: 122), is different in each school: Moreover, our expert is convinced that the subject of discrimination could be brought into the whole teaching body because one third of the pupils "represent the school conference and anyway "school is such a flowing system" (SP_1: 78-80). Also, teachers as most influential and powerful part of school culture have to learn as also discrimination exists among these reflective professionals. As the other side of the coin between Established and Outsiders we learned that a high self-image could hinder learning progress. If, for example, by teachers, discriminations "are not looked at during the break because, for whatever reason, they are not so motivated" and "are overloaded", consequently "no culture" develops. (SP_1: 103f.). Against the background of permanent social distinctions, however, the expectation of creating good school culture developed specifically:

"The educational common ground means: We have these rules. We pull them through. They know how to act. They know that they will get support when they see rules being broken. Then they know in which order which consequences will follow for this student. And they can announce that. They can go through with that, and they get a bit of support from the school management that it's okay. That would be desirable" (SP_1: 110).

Finally, we will present what happened to our qualifications and trainees against this background. The participants trusted in the classic administration processes in order to implement school culture, i.e. teachers could use their authority to issue instructions. However, this scope for action was not communicated in the course of the project, which was to be conveyed to the participants. In this specific figuration the participant's desire to ensure sustainability in a discrimination-sensitive school culture and institutional support from the school management and district government could initially only be achieved through a specific interaction: (social) research, organized expertise and teaching methods (tool kit) as well as legal guide on the AGG and important contact points.

\section{Requirements in the network of administrative paths}

The resistance as well as successes that are discussed here at the end show that it is both difficult and rewarding to accompany a change in school culture. The schools and the district government reacted differently to the

\footnotetext{
${ }^{6}$ School culture is in the context of the already diffuse concept of organizational culture and here constitutes a field-specific term to be determined.
} 
cooperation and qualification offers coming from outside of their traditional organizational structure. Contrary to a directly addressing of school leaders, only through support of the district government was there access to the school management, who ultimately sent teachers. Nevertheless, in the course of the project, a highly heterogenous school (80\% national diversity) dropped out during the process and was unable to take the opportunity to develop its school further in this regard. It could not be determined in this context whether the strong discrimination findings from the student survey were interwoven in the competition for potential pupils. Another problematic aspect became obvious after the qualification had ended: the compensation for the training hours had not been equally binding and sufficiently communicated and implemented with the school management. This not only slowed the very committed and, above all, young teachers in the qualification measure, but also made them considerably frustrated. Despite these organizational adversities, that are of course a product of hierarchical structures in our research field, in the development process of the schools involved at school and project policy level, successful steps were taken to further develop the respective school culture. In some cases, the eight schools involved (comprehensive school, grammar school and college) were already trained and sensitized as one of the almost 110 project schools in North-Rhine-Westphalia ("School Without Racism", "School With Courage"). In other cases, the topic was introduced for the first time, for example as a teaching unit in history, social or religious studies. School development as educational organizational development also aims to continuously reflect and professionalize school processes with a focus on teaching (Ernst 2003a; Foitzik et al. 2019).

It relates both to organization-specific standards for reflecting on school work and, with the aid of accompanying scientific research, to guidelines that the evaluation specifies. This includes, on the one hand, defining quality criteria, collecting and analyzing process data and tailoring them precisely to the information needs of schools. ${ }^{7}$ The key here are the quality features, clear and practical feedback to be provided, data to be offered in different aggregate levels and short periods of time to be provided between the survey and the feedback. In addition to the ongoing feedback of results, environmental studies by the schoolchildren, which can be followed up using the population survey and their own empirical close-up analyzes (using computer-aided methods such as GrafStat, LimeSurvey or Survey Monkey), also served to ensure comprehensive participation by the school actors.

On the other hand, the question of suitable measures, such as whether and to what extent a school's own discrimination monitoring should be aimed for, remained just as open in the end as the sustainable infrastructural security and institutionalization of the initiated reflection processes. To reconcile these demands and objectives for school practice with the already grown quality requirements is currently the central problem of school development processes (Foitzik, Hezel 2019). The organizational process sometimes increases permanent tensions, because less "resources are overloading the educational staff, increasing noticeably great frustration" among teachers and families. Through this, an initial "openness as well as willingness to learn and develop" on the part of everyone could even, in the opposite "consequence, promote a negative attitude towards fundamental democratic and human rights-related changes” (Andrades et al. 2016: 100).

\section{CONCLUSION}

To sum up, first, social ambivalences expressed in our data can be understood as a result of successful informalisation processes against the background of regulated formalisation processes. The discourse on plurality and diversity, on the other hand, shows new and further lines of conflict and social differentiation too. Thus, the open speech about feelings of inferiority and professional ideals of equivalence is part of social spurts and counter-spurts of social change. These processes require a reflective, situational handling of external and self-constraints concerning feelings

\footnotetext{
${ }^{7}$ While process quality affects not only the central role of teachers in asymmetric, collective school and teaching practice, but also the unplanned process in classroom and teaching practice, structural quality includes the infrastructure (from personnel keys to building condition to investments) as well as noise pollution in schools (Ernst 2008; Stiller 2015). Finally, quality of results explicates the successful, in this case, achievement of class goals and school leaving certificates.
} 
of superiority and inferiority. Besides well-known historical developments (Ernst 2003b) nowadays the tolerance of these emotions is part of social spurts and counter-spurts of intended but undirected social change. Expressed in progressive legislation, changed public norms, state equality policies, contemporary and recent debates on discrimination and sexism and nevertheless the need to collaborate with experts for social equality, such as those interviewed in this presented project. This change can also be interpreted as an effect of the formalisation-informalisation span between Established and Outsiders. Cases of bullying, sexism, racism on the one hand show that the ability to identify one another is not all embracing developed in social groups at whole. On the other, emancipation gains can be recognized in the possibility to sanction uncivilised misbehavior by law i.e. the AGG or European rights.

Second, besides being not only an institution school is an organization and as a special figuration facing the paradox challenge to balance justice and equality of educational opportunities in purposeful and targeted, cooperative membership structures that permanently generate social inequality. Anti-discrimination politics are moreover a product of social and organizational change. A diversity-sensitive process organization is just as necessary here as a reflective quality development considering the particularly sensitive network of actors of students, teaching staff and parents with professional "complaint structures" (Foitzik, Hezel 2019: 118). Not only the teachers to be qualified, but also the experts questioned have increasingly requested this. In addition, this exemplary excerpt indicates that the necessary sanctions are missing in the Anti-Discrimination Law and that overall more structural knowledge can be disseminated. With regard to an innovative school culture in which discrimination seems so little tangible, this means that ombudsmen, independent out-of-school or in-school complaints and contact points and arbitration programs should be introduced or continued and last not least anti-discrimination guides should be trained. It is particularly relevant for discrimination that school (re-)produces the tension between expected and experienced affiliation in the wake of long-term social mobility processes. It is well known (Bourdieu 2001) that institutional discrimination is particularly effective in so-called "educationally distant" milieus (Hormel, Riegel 2019). A reflective organizational development has to counter the risk that the work intensification that always accompanies social innovations can be disavowed. If schools that are sensitive to discrimination want to depict more than one legitimation facade, system-appropriate and realistic goals must be formulated. A more achievable goal may be to speak of discrimination-sensitive rather than non-discriminatory work, teaching and learning. Schools are only at the beginning of discrimination-sensitive quality development processes and (due to their structural logics and tensions) far away from the claim to freedom from discrimination. This can persistently implicate internal conflicts and hinders the development of an error-friendly climate in school. The main problem at present is to reconcile these demands on practice with the quality requirements that have already grown (Foitzik, Hezel, 2019). It therefore also remains unclear how a sustainable change in school culture can be brought about and, above all, evaluated. Further integrating scientific expertise seems to be necessary for the future in order to process the indicators for school culture developed in the field (e.g. educational common ground, rules, support, transparent conflict and process management, support, relief and stress plans) with and in schools.

We are part of this process of balancing new and more equal rights and organizational learning that can better be understood in a figurational perspective of "engaged social distance".

\section{REFERENCES}

AGG. (2020), Allgemeines Gleichbehandlungsgesetz, ed. by Antidiskriminierungsstelle des Bundes, Berlin. 13. edition

Andrades E.M., El M., Schütze D. (2016), Bildungspolitik und Schule in der Verantwortung für eine nichtdiskriminierende demokratische Gesellschaft. Ideologien der Ungleichbeit, Schriften zur Demokratie, 42, Eine Publikation des Stiftungsverbundes der Heinrich-Böll-Stiftung, 93-125.

Bourdieu P. (2001), Wie die Kultur zum Bauern kommt. Über Bildung, Schule und Politik, Hamburg: VSA.

Böhle F. (2019), Humane Arbeit als geistige Arbeit?, in Fritz Böhle and Eva Senghaas-Knobloch (eds.) Andere Sichtweisen auf Subjektivität. Impulse für kritische Arbeitsforschung, 9-36.Wiesbaden: Springer VS. 
Calmbach M., Flaig B., Edwards J., Möller-Slawinski H., Borchard I., Schleer C. (2020, eds), Wie ticken Jugendliche? Lebenswelten von Jugendlichen im Alter von 14 bis 17 Jabren in Deutschland. Eine SINUS-Studie, Bonn: Bundeszentrale für politische Bildung.

Drepper T., Tacke V. (2012), Die Schule als Organisation, in M. Apelt, V. Tacke (eds), Handbuch Organisationstypen, 205-237, Wiesbaden: Springer VS.

El-Mafaalani A. (2018), Das Integrationsparadox. Warum gelungene Integration zu mehr Konflikten führt, Köln: Kiepenheuer und Witsch.

Elias N., Scotson J.L. ([1965] 2008), The Established and the Outsiders, Collected Works of Norbert Elias, Vol. 4. University College Dublin Press, Dublin.

Elias N. (1978), What Is Sociology?, New York: Columbia University Press.

Ernst S. (2003a), Externe Schulevaluation in Kooperation: Konflikte im Spannungsfeld von Praxisforschung und angewandter Organisationsberatung. Sozialwissenschaften und Berufspraxis 26 (3):269-284.

Ernst S. (2003b), From Blame Gossip to Praise Gossip? Gender, Leadership and Organizational Change, in «The European Journal of Women's Studies», 10(3):277-299.

Ernst S. (2008), Manual Lehrevaluation, Wiesbaden: Springer VS.

Ernst S. (2010), Prozessorientierte Methoden in der Arbeits- und Organisationsforschung, Wiesbaden: Springer VS.

Ernst S. (2013), Theorizing and Practizing Organizational Culture and Diversity. A Case Study, in «Cambio. Rivista sulle trasformazioni sociali», 3(6):197-210.

Ernst S., Heyse M., Marej K. (2020), SPRYNG. Auswertung der CATI-Befragung im Regierungsbezirk Münster, BEMA Working Paper No.8. (30.June 2020, https://www.uni-muenster.de/imperia/md/content/soziologie/ bema/berichte/bema-paper_ausgabe_8_ende.pdf

Ernst S. 2021. SPRYNG-Spreading Young Non-discrimination Generation. Diskriminierung im Regierungsbezirk Münster. Ausgewählte Ergebnisse des Projektes SPRYNG https://www.uni-muenster.de/imperia/md/content/ soziologie/bema/berichte/bema-paper_ausgabe_9.pdf

Foitzik A., Hezel L.J. (2019 eds.), Diskriminierungskritische Schule: Einfübrung in theoretische Grundlagen, Weinheim: Beltz.

Foitzik A., Holland-Cunz M., Riecke C. (2019), Praxisbuch Diskriminierungskritische Schule, Weinheim: Beltz.

Gomolla M. (2019), Evaluationsstudie Qualitätsentwicklung von Schule in der Migrationsgesellschaft: Fortbildung zur interkulturellen Koordination, in «Zeitschrift für Diversitätsforschung und -management», 4(12):117-123.

Hauenschild K., Robak S., Sievers I. (2013, eds), Diversity Education Zugänge - Perspektiven - Beispiele, Frankfurt am Main: Brandes and Apsel.

Herzog W. (2011), Schule und Schulklasse als soziale Systeme, in R. Becker (eds.), Lehrbuch der Bildungssoziologie, 163-202, Wiesbaden: Springer VS.

Hormel U., Riegel. C. (2019), „Sarrazin musste das Bild der bildungsfernen Migrant*innen nicht erst erfinden."Schule und institutionelle Diskriminierung. Ein Gespräch, in A. Foitzik and L. J. Hezel (eds), Diskriminierungskritische Schule: Einführung in theoretische Grundlagen, 150-164, Weinheim: Beltz.

Kaluza C. (2017), Diversity Management und Schulentwicklung, in C. Kaluza, B. Schimek (eds), Diversity Management in Schulen, 89-115. Bochum: Projektverlag.

Mecheril P., Tißberger M. (2013), Ethnizität und Rassekonstruktion. Ein rassismuskritischer Blick auf Differenzkategorien, in K. Hauenschild, S. Robak and I. Sievers (eds.), Diversity Education Zugänge - Perspektiven Beispiele, 60-71, Frankfurt am Main: Brandes and Apsel.

Sowada M.G., Peetz T. (2019), Schulen beurteilen. Grammatik und Pragmatik der Bewertung in Schulinspektionsteams, in (eds) C. Imdorf, R. J. Leemann and P. Gonon (eds), Bildung und Konventionen. Soziologie der Konventionen, 205-226, Wiesbaden: Springer VS.

Stiller M. (2015), Belastungen, Ressourcen und Beanspruchungen bei Lehrkräften, Bad Heilbrunn: klinkhardt.

Supik L. (2017), Statistik und Diskriminierung, in A. Scherr, A. El-Mafaalani and G. Yüksel (eds.), Handbuch Diskriminierung, 191-208. Wiesbaden: Springer VS. 
Te Poel K.. (2018), Missachtungserfahrungen infolge einseitiger Adressierungen von Schüler*innen als kognitive Leistungserbringer. Konsequenzen für eine anerkennungssensible Lebrer*innenbildung, in «DDS-Die Deutsche Schule», 110(4):341-353.

Treibel A. (2015), Integriert Euch. Plädoyer für ein selbstbewusstes Einwanderungsland, Frankfurt am Main: Campus.

Wouters C. (2014), Universally applicable criteria for doing figurational process sociology. Seven balances, one triad, in «Human Figurations», 3 (1), https://quod.lib.umich.edu/h/humfig/11217607.0003.106/--universally-applicable-criteria-for-doing-figurational?rgn=main;view=fulltext (accessed:17 June 2020).

\section{Online-Sources:}

Ministerium für Schule und Bildung des Landes Nordrhein-Westfalen. 2019. NRW Schulgesetz: Schul- und Bildungsgesetze des Landes Nordrhein-Westfalen.https://bass.schul-welt.de/6043.htm (5.March 2020]. 